University of Nebraska - Lincoln

DigitalCommons@University of Nebraska - Lincoln

Biochemistry -- Faculty Publications

Biochemistry, Department of

8-2016

\title{
Loss of Exogenous Androgen Dependence by Prostate Tumor Cells Is Associated with Elevated Glucuronidation Potential
}

\author{
Brenna M. Zimmer \\ University of Nebraska-Lincoln \\ Michelle E. Howell \\ University of Nebraska-Lincoln, michelle.palmer@unl.edu \\ Qin Wei \\ University of Nebraska-Lincoln \\ Linlin $\mathrm{Ma}$ \\ University of Nebraska-Lincoln \\ Trevor Romsdahl \\ University of Nebraska-Lincoln
}

Sellowext tha pandfadditionahworks at: https://digitalcommons.unl.edu/biochemfacpub

Part of the Biochemical Phenomena, Metabolism, and Nutrition Commons, Biochemistry Commons, Biological Phenomena, Cell Phenomena, and Immunity Commons, Biotechnology Commons, Medical Biochemistry Commons, Neoplasms Commons, Other Biochemistry, Biophysics, and Structural Biology Commons, and the Reproductive and Urinary Physiology Commons

Zimmer, Brenna M.; Howell, Michelle E.; Wei, Qin; Ma, Linlin; Romsdahl, Trevor; Loughman, Eileen G.; Markham, Jennifer E.; Seravalli, Javier; Barycki, Joseph J.; and Simpson, Melanie A., "Loss of Exogenous Androgen Dependence by Prostate Tumor Cells Is Associated with Elevated Glucuronidation Potential" (2016). Biochemistry -- Faculty Publications. 226.

https://digitalcommons.unl.edu/biochemfacpub/226

This Article is brought to you for free and open access by the Biochemistry, Department of at DigitalCommons@University of Nebraska - Lincoln. It has been accepted for inclusion in Biochemistry -- Faculty Publications by an authorized administrator of DigitalCommons@University of Nebraska - Lincoln. 


\section{Authors}

Brenna M. Zimmer, Michelle E. Howell, Qin Wei, Linlin Ma, Trevor Romsdahl, Eileen G. Loughman, Jennifer E. Markham, Javier Seravalli, Joseph J. Barycki, and Melanie A. Simpson 
Published in final edited form as:

Horm Cancer. 2016 August ; 7(4): 260-271. doi:10.1007/s12672-016-0268-z.

(c) 2016 Springer International Publishing. Part of Springer Nature.

\title{
Loss of exogenous androgen dependence by prostate tumor cells is associated with elevated glucuronidation potential
}

\author{
Brenna M. Zimmer ${ }^{1}$, Michelle E. Howell ${ }^{1}$, Qin Wei, Linlin Ma, Trevor Romsdahl, Eileen \\ G. Loughman, Jennifer E. Markham, Javier Seravalli, Joseph J. Barycki, and Melanie A. \\ Simpson* \\ Department of Biochemistry, University of Nebraska, Lincoln, NE
}

\begin{abstract}
Prostate epithelial cells control the potency and availability of androgen hormones in part by inactivation and elimination. UDP-glucose dehydrogenase (UGDH) catalyzes the $\mathrm{NAD}^{+}$dependent oxidation of UDP-glucose to UDP-glucuronate, an essential precursor for androgen inactivation by the prostate glucuronidation enzymes UGT2B15 and UGT2B17. UGDH expression is androgen stimulated, which increases the production of UDP-glucuronate, and fuels UGT-catalyzed glucuronidation. In this study, we compared the glucuronidation potential and its impact on androgen-mediated gene expression in an isogenic LNCaP model for androgen dependent versus castration resistant prostate cancer. Despite significantly lower androgenglucuronide output, LNCaP 81 castration resistant tumor cells expressed higher levels of UGDH, UGT2B15, and UGT2B17. However, the magnitude of androgen-activated UGDH and PSA expression, as well as the AR-dependent repression of UGT2B15 and UGT2B17, was blunted several-fold in these cells. Consistent with these results, the ligand-activated binding of AR to the PSA promoter and subsequent transcriptional activation were also significantly reduced in castration resistant cells. Analysis of the UDP-sugar pools and flux through pathways downstream of UDP-glucuronate production revealed that these glucuronidation precursor metabolites were channeled through proteoglycan and glycosaminoglycan biosynthetic pathways, leading to increased surface expression of Notch 1. Knockdown of UGDH diminished Notch1 and increased glucuronide output. Overall, these results support a model in which the aberrant partitioning of UDP-glucuronate and other UDP-sugars into alternative pathways during androgen deprivation contributes to the loss of prostate tumor cell androgen sensitivity by promoting altered cell surface proteoglycan expression.
\end{abstract}

\section{Keywords}

prostate cancer; castration resistance; dihydrotestosterone; detoxification; LNCaP

\footnotetext{
${ }^{*}$ To whom correspondence should be addressed: Dr. Melanie A. Simpson, Department of Biochemistry, University of Nebraska, N246 Beadle Center, Lincoln, NE 68588-0664; Tel (402) 472-9309; msimpson2@unl.edu.

These authors contributed equally to this publication.

The authors have no conflicts to declare.
} 


\section{Introduction}

Prostate cancer is the most commonly diagnosed cancer in men [1]. Locally advanced cancer that is present at first diagnosis is often inoperable and treated by androgen deprivation therapy [2]. Most tumors respond initially, but recurrence is a serious clinical problem because tumor cells that resume growth despite low circulating androgen are highly aggressive [3, 4]. A major cause of mortality in prostate cancer is castration resistant recurrence $[5,6,2]$, but the underlying molecular mechanisms are not yet fully understood and are therefore an area of intense research focus. It is well accepted that tumor cells can acquire the ability to synthesize androgens locally [7] or develop aberrant androgen receptor (AR) functions through post-transcriptional and post-translational modifications that eliminate the need for exogenous androgen [8, 9]. However, less is known about the impacts of androgen elimination pathways on castration resistant progression.

Excess androgen is normally managed by the glucuronidation pathway, in which steroids or other lipophiles are chemically inactivated and solubilized by conjugation to glucuronate moieties. UDP-glucuronosyltransferase (UGT) enzymes are expressed in hormone-sensitive target tissues and catalyze the esterification of a steroid hydroxyl to the anomeric carbon of UDP-glucuronate (UDP-glcA), yielding the androgen-glucuronide with UDP as a leaving group [10]. The net effect is to maintain levels of critical lipophilic hormones in the concentration windows at which they are most effective in engaging their receptors. Prostate epithelial cells express two UGT isoforms, UGT2B15 and UGT2B17 [11]. Cell culture experiments show that expression of these $95 \%$ identical isoforms is androgen repressed and their overexpression reduces the proliferation rate of cells by increasing inactivation of androgens [12-15]. Importantly, polymorphisms in both genes have been identified and correlated as genetic risk factors for prostate cancer [16, 17]. In addition, comparison of castration resistant murine and human prostate tumor metastases to primary tumors revealed increased expression of UGT2B17 in conjunction with increases in several androgen biosynthetic enzymes [18].

UDP-glucose dehydrogenase (UGDH) is a unique, essential enzyme that catalyzes oxidation of UDP-glucose to UDP-glcA, which is the required precursor for glucuronidation. Many tissues express UGDH, but strong expression is specific to liver and prostate [19], both tissues that actively demand glucuronate conjugation to facilitate hormone excretion. We previously showed that stimulating UGDH expression and consequently increasing UDPglcA cofactor availability can drive UGT-catalyzed glucuronidation by mass action in androgen dependent prostate tumor cells [20]. We have also found that UGDH expression is significantly elevated in epithelial cells of cancerous prostate acini relative to those of both normal prostate or those of normal appearing acini at the tumor/normal interface in biopsied samples [21].

In the current study, our goal was to characterize the function of the glucuronidation pathway during loss of androgen dependence, and determine the effects of altered androgen availability on the component enzymes and metabolite intermediates. We used an isogenic cell culture model of androgen dependent and castration resistant prostate cancer, LNCaP 33 and $\mathrm{LNCaP} 81$. LNCaP 81 was derived from LNCaP 33 by long-term passage in androgen- 
containing culture conditions to achieve a cell population that remained androgen responsive but was no longer androgen dependent [22]. We tested the effect of short-term and prolonged androgen deprivation on AR-dependent gene expression and activity of UGDH, UGT2B15, UGT2B17, and the UDP-sugar metabolites. We found that androgen sensitive $\mathrm{LNCaP} 33$ cells retained greater dynamic potential for AR-mediated gene expression and androgen-glucuronide secretion, while the LNCaP 81 counterparts partitioned UDP-glcA into increased synthesis of glycosaminoglycans. We confirmed these properties in 22Rv1 cells, which are also a model for castration resistant prostate cancer. In addition, we reduced UDP-glcA by knocking down UGDH, which resulted in diminished proteoglycan production and increased androgen glucuronide output. These results are consistent with a model in which the altered flux of UDP-sugar intermediates through multiple downstream pathways blunts the function of the glucuronidation pathway and promotes intracellular androgen accumulation to sustain cellular proliferation in the absence of exogenous steroids.

\section{Materials and Methods}

\section{Reagents}

All reagents were obtained from Fisher Scientific (Pittsburgh, PA) except where indicated. 5-a-dihydrotestosterone (DHT) and DHT-glucuronide were from Sigma (St. Louis, MO). Charcoal stripped FBS was from Hyclone (Logan, UT). Antibodies were purchased and used as follows: polyclonal rabbit anti-human PSA (DakoCytomation, Glostrup, Denmark, 1:1500 dilution); mouse monoclonal anti-human $\beta$-tubulin (Sigma, 1:750,000); IRDye 800 conjugated anti-rabbit IgG (Rockland, Gilberstville, PA, 1:5000); IRDye 680 conjugated goat anti-mouse IgG (LI-COR Biosciences, Lincoln, NE, 1:5000); rabbit polyclonal antihuman UGT2B17 (1:100) and rabbit polyclonal anti-human HSD17B3 (GeneTex, Irvine, CA, 1:500); mouse monoclonal anti-human AR (Santa Cruz Biotechnology, Inc, Dallas, TX, 1:500); rabbit monoclonal anti-human Notch 1 (Cell Signaling Technology, Danvers, MA, 1:1000); mouse monoclonal anti-human HSD3B1 (1:100) and rabbit monoclonal anti-human ARv7 (Abcam, Cambridge, MA, 1:1000). Rabbit polyclonal anti-human UXS1 was raised against purified recombinant human UXS1, residues 85-420 (Pocono Rabbit Farms). The UXS1 expression construct was a gift from Nicola Burgess-Brown: Addgene plasmid \# 39162.

\section{Cell culture and selection of stable lines}

LNCaP (denoted LNCaP 33 herein), 22Rv1, and PC3 human prostate adenocarcinoma cells were purchased from American Type Culture Collection (Manassas, VA), and maintained in culture for a maximum of ten passages after thaw. LNCaP 81 androgen independent cells were kindly provided by Dr. Ming-Fong Lin ([23] University of Nebraska Medical Center, Omaha, NE). For standard culture, PC3 was maintained in MEM supplemented with 10\% FBS, non-essential amino acids, and sodium pyruvate; LNCaP and 22Rv1 lines were maintained in RPMI-1640 supplemented with $10 \%$ FBS, all as recommended by the vendor. To generate UGDH knockdown lines, LNCaP 33 cells were transfected with plasmids encoding shRNA targeted to UGDH or a scrambled non-targeting control (UGDH shRNApGFP-V-RS \#TG334012 and 29-mer oligo-pGFP-V-RS \#TR30008, respectively, from Origene Technologies, Rockville, MD). Stable integration of the shRNA plasmids was 
achieved by clonal selection in RPMI-1640 with $10 \% \mathrm{FBS}$ and $1 \mu \mathrm{g} / \mathrm{ml}$ puromycin. Once selected, clones were maintained in the same medium containing $0.5 \mu \mathrm{g} / \mathrm{ml}$ of puromycin. Two clones of each were chosen for full characterization. Clones designated KD1 and KD2 had $>70 \%$ reduced UGDH protein expression relative to the two control clones designated $\mathrm{C} 1$ and $\mathrm{C} 2$ with UGDH expression identical to the parental line.

\section{Androgen stimulation}

For short-term comparison of androgen response, $\mathrm{LNCaP}$ cells were subcultured to $50 \%$ confluence in phenol red-free RPMI-1640 supplemented with 1\% charcoal stripped FBS (CS-FBS) for $48 \mathrm{~h}$ (androgen-depleted conditions). DHT was serially diluted into media from concentrated stocks solubilized in ethanol as a vehicle. Androgen-depleted media were replaced with media containing the indicated concentration of DHT for $48 \mathrm{~h}$, and harvested for analysis. For long-term selection, cells were grown for 10 days in phenol red-free RPMI-1640 media containing 5\% CS-FBS and 0 (vehicle), $0.1,1$, or $10 \mathrm{nM}$ DHT. Media were renewed every two days. Following selection, cells were either maintained in these conditions, or subjected to $48 \mathrm{~h}$ in androgen-depleted media followed by 24-48 h stimulation with $10 \mathrm{nM}$ DHT to quantify the magnitude of the androgen-stimulatable response.

\section{Western analysis}

Cells were scraped into cold PBS following treatments, pelleted by centrifugation, and lysed in 1x RIPA buffer with protease inhibitor cocktail. Protein was quantified by Bradford assay and equivalent amounts of total protein were analyzed. UGDH (rabbit polyclonal antihuman UGDH, 1:5000, [20]), AR, PSA, and $\beta$-tubulin were probed simultaneously in cell lysates. UGT2B17, UXS1, Notch 1, ARv7, HSD3B1, and HSD17B3 were each probed separately with $\beta$-tubulin on identical blots. Following secondary incubation, protein expression was quantified by fluorescence emission using the Odyssey Infrared Imaging System (LI-COR Biosciences, Lincoln, NE). Signals for each wavelength were analyzed in red (700 nm, tubulin and HSD3B1) and green $(800 \mathrm{~nm}$, all other targets), to normalize protein expression. Statistical significance was assessed by Student's t-test. Each densitometric analysis is plotted for three technical replicates of a representative experiment that was repeated at least three times.

\section{Detection of UDP-glucuronosyltransferase mRNA expression}

Total RNA was isolated from LNCaP 33 and 81 cells that had been cultured in different concentrations of androgen for 3-10 days and then treated with vehicle or $10 \mathrm{nM}$ DHT for another $48 \mathrm{hrs}$. Equivalent amounts of total RNA were reverse transcribed; the UGT2B15 and UGT2B17 coding sequences were amplified by PCR as previously published [20].

\section{Quantification of UDP-sugars and androgen glucuronide conjugates}

Lysates from the indicated lines and treatments were extracted with butanol-saturated concentrated formic acid and analyzed for UDP-sugar content by liquid chromatography and mass spectrometry (LC-MS) according to published methods [24, 25]. Conditioned media 
from androgen treated cell cultures were ethanol extracted for glucuronide analysis by LCMS/MS, also as published [20]. Statistical significance was assessed by Student's t-test.

\section{Chromatin immunoprecipitation}

LNCaP 33 and 81 were selected in DHT for $48 \mathrm{~h}$ or for 10 days. Media were removed and replaced with media containing vehicle or $10 \mathrm{nM}$ DHT for $16 \mathrm{~h}$ prior to ChIP assay. After AR immunoprecipitation, qPCR was done using primers for the PSA enhancer element, PSA basal promoter (negative control) and actin (normalization control)[26]. AR bound to the PSA enhancer was plotted as \% input (fraction of total AR immunoprecipitated DNA that was amplified by gene-specific primers) from a single assay done in triplicate that is representative of at least three separate selection trials per condition. Amplification of DNA from the basal promoter was confirmed to be $<0.02 \%$ as expected for all conditions (not shown).

\section{Luciferase reporter assay}

LNCaP 33 and 81 cells were grown in RPMI-1640 media containing 5\% CS-FBS. After 10 days of selection with $0,0.1,1,10 \mathrm{nM}$ of DHT, cells were transfected with pGL3-basic-Luc + pRL-SV40 Renilla plasmids, or pGL3-PSA-Luc + pRL-SV40 Renilla plasmids. 24 hrs after transfection, cells were treated with vehicle or $10 \mathrm{nM}$ DHT. After another $24 \mathrm{hrs}$, cells were harvested for luciferase assay using the Promega Dual Luciferase kit according to manufacturer instructions. Each experiment was done in triplicate wells and luciferase activities were normalized.

\section{Results}

\section{Androgen dependent LNCaP cells have lower levels of glucuronidation enzymes and greater dynamic range in AR-mediated gene expression}

We previously showed that UGDH was an androgen-stimulated gene, and that its elevation by DHT administration produced up to 6-fold more DHT-glucuronide secretion by LNCaP 33 compared to LNCaP 81 cells [20], which model the androgen dependent versus castration resistant states of prostate cancer, respectively. To examine the impact of castration resistance on the glucuronidation pathway and AR-mediated gene expression, we exposed LNCaP 33 and 81 cells to two days of androgen-deficient media followed by an additional two days of vehicle $(0 \mathrm{nM})$ or the indicated concentrations of DHT. As expected, UGDH expression was diminished in $\mathrm{LNCaP} 33$ cells in the absence of DHT and restimulated at physiological doses (1 nM and $10 \mathrm{nM}$ DHT, Fig 1A). UGDH levels were higher at all DHT doses in LNCaP 81 cells, and were not altered by androgen withdrawal. Also as expected, PSA expression was virtually absent in both lines without DHT, and restimulated expression was >10-fold higher in androgen sensitive LNCaP 33 cells (Fig 1B). AR expression, which is modestly suppressed by DHT, was $\approx 30 \%$ lower in LNCaP 81 cells than in 33 cells (Fig 1C). UGT2B17 expression was upregulated in the absence of DHT in both LNCaP 33 and 81 cells, but while the levels were potently suppressed by DHT in a dose dependent manner in LNCaP 33 cells, DHT treatment did not significantly reduce the elevated expression in LNCaP 81 cells (Fig 1D). Similar results were obtained using 22Rv1 cells, which express wild-type AR and are mildly androgen responsive but not androgen dependent (Fig S1A- 
S1D). In these cells, UGDH and UGT2B17 were also elevated, while PSA and AR expression were reduced, and levels were not altered by DHT. PC3 cells, which lack AR expression, also did not have PSA, appreciable levels of UGT2B17, or DHT-sensitive UGDH upregulation (Fig S1A-S1D). Collectively, these results show that the magnitude of both AR-mediated activation and repression was significantly reduced in the castration resistant state. Moreover, despite reduced DHT-glucuronide secretion, LNCaP 81 cells had elevated expression of the glucuronidation pathway enzymes UGDH and UGT2B17.

\section{Prolonged androgen depletion leads to dose dependent decreases in basal and androgen-stimulated gene expression}

Increased UDP-glcA production by UGDH can drive androgen inactivation and thereby modify tumor cell growth in androgen responsive cells. If UGDH is a causative factor in these phenomena, its expression levels should be influenced by prolonged exposure to different DHT concentrations and translate to direct effects on AR-mediated gene expression. To test this, we selected LNCaP 33 and 81 cells for 10 days in androgen free media that were supplemented with 10 -fold decrements of DHT from $10 \mathrm{nM}$ to $0 \mathrm{nM}$ (vehicle). We then examined the effects of selection on gene expression and AR transcriptional activity in the unstimulated and androgen treated states, to observe both basal impact and changes in responsiveness to hormones.

After selection for 10 days in androgen free media, UGDH basal expression in LNCaP 33 cells was significantly reduced and could be stimulated 3.5-fold by re-introduction of DHT, while UGDH levels did not change in LNCaP 81 cells (Fig 2A shows relative stimulation). The drop in basal UGDH expression specifically in LNCaP 33 cells suggests that the provision of androgen from extracellular sources is necessary to sustain high levels of UGDH protein in these cells. Selection in the lowest concentration of androgen $(0.1 \mathrm{nM})$ preserved UGDH expression such that only $\approx 1$.6-fold stimulation was observed upon restoration of DHT (Fig 2A). In $1 \mathrm{nM}$ or $10 \mathrm{nM}$ conditions, no loss of UGDH expression was observed and no further stimulation occurred. That is, basal and stimulated UGDH expression was the same in LNCaP 33 and 81 cells that were selected in at least $1 \mathrm{nM}$ DHT (Fig 2A). Thus, 1-10 nM DHT treatment appeared to be both necessary and sufficient to maintain UGDH expression in androgen sensitive cells. However, it is notable that this level of regulation was lost in cells that do not respond to exogenous DHT. We reprobed these western blots for PSA and for AR expression (Fig 2B). Similar dose dependent loss of expression was observed for PSA in both LNCaP 33 and 81 cells after selection, though as in the short-term treatments, PSA expression at all levels was significantly lower in LNCaP 81 than in LNCaP 33. Expression of AR protein was not altered by selection.

\section{Extended androgen depletion elevates expression of UGT2B17 and reduces sensitivity of UGT2B15 and UGT2B17 to DHT suppression}

AR has been shown to mediate DHT-induced suppression of UGT isoforms UGT2B15 and UGT2B17 in dose dependent fashion within a 24-hour time period [27]. Since mass action glucuronidation driven by UGDH requires UGT activity, we next quantified effects of differential androgen selection on basal and DHT-suppressible UGT expression. LNCaP 33 and 81 cells were cultured in androgen depleted media for ten days and expression was 
compared by qRT-PCR at an early time point (three days) and at endpoint. Selection for 10 days modestly elevated expression of UGT2B 15 in both LNCaP 33 and 81 cells relative to the 3-day time point, but UGT2B 17 expression was $\approx 5$-fold and $\approx 3.5$-fold increased in LNCaP 33 and 81 cells, respectively (Fig 3A). It should be noted that although levels are normalized to emphasize pairwise fold comparison in the figure, expression of both isozymes was significantly higher in LNCaP 81 cells than in LNCaP 33 cells at three days. This finding is consistent with the short-term results in Figure 1, and suggests there is a loss of ligand-dependent AR activity at the UGT promoters.

We next selected LNCaP 33 and 81 cells in androgen decrements for 10 days, followed by a 24 hour treatment with vehicle or DHT, and evaluated UGT2B15 and UGT2B17 expression by qRT-PCR (Fig 3B and 3C). Expression was normalized to its respective level at $0 \mathrm{nM}$ DHT in the untreated samples. The expression of both UGT isozymes was 3-20-fold higher in LNCaP 81 than in 33 cells. In both lines, the degree to which DHT suppressed either isozyme was significantly reduced when cells were selected in the complete absence of DHT. In LNCaP 33 cells (Fig 3B and 3C), both UGT2B15 and UGT2B17 were sensitive to suppression by DHT treatment in all doses. UGT2B 15 basal expression was relatively stable at all selection doses and suppressed by addition of $10 \mathrm{nM}$ DHT as expected (Fig 3B, left panel). Inhibition of basal UGT2B17 expression in LNCaP 33 cells was $\approx 65 \%$ at $0.1 \mathrm{nM}$ DHT selection and further suppressed $(\approx 90 \%)$ at higher doses (Fig 3C, left panel). Upon 24hour treatment with DHT, expression was diminished by $55 \%$ if cells were selected in the complete absence of DHT, but up to $>95 \%$ for all selection doses. Such strong regulation was not observed for the LNCaP 81 cells, though selection in DHT reduced UGT2B17 basal and stimulated levels by $\approx 50 \%$. Thus, selection conditions profoundly impact regulation of UGT in prostate cells.

\section{Androgen deficient selection impacts ligand dependent AR binding and transcriptional activation of the PSA promoter/enhancer}

Since AR regulates PSA expression, the lack of correlation between AR protein and restimulation of PSA after selection suggested an impact of selection on AR activity. To examine this, we used chromatin immunoprecipitation (ChIP) to quantify AR bound to the PSA androgen response element as previously described [28]. Cells were selected in decreasing androgen as indicated in the legend for a 10-day period and assayed by ChIP after a 16 hour treatment with or without $10 \mathrm{nM}$ DHT (Fig 4A). As a positive control, results of the 10-day selection were compared to cell cultures selected for only $48 \mathrm{~h}$ before final DHT treatment, which were the conditions used in prior experiments [20]. Basal AR bound to the PSA enhancer was minimal in both cell lines whether cells were selected for $48 \mathrm{~h}$ or 10 days unless first treated with DHT (Fig 4A, "DHT in ChIP": 0 nM illustrates basal AR bound, $10 \mathrm{nM}$ DHT added illustrates ligand-activated AR bound, indicated on the x-axis). In LNCaP 33 cells, presence of DHT in the selection media increased AR occupancy at the PSA enhancer in a dose dependent manner. Prolonged selection in low or no androgen strongly reduced the level of AR that could be stimulated to bind the PSA enhancer upon subsequent $10 \mathrm{nM}$ DHT addition, relative to the $48 \mathrm{~h}$ treatment. In LNCaP 81 cells, less AR was bound to the PSA enhancer at all doses, which was only partially attributable to the reduced expression of AR in those cells, and DHT addition also did not stimulate 
appreciable AR binding. To examine AR transcriptional activation, we used a luciferase reporter driven by the PSA promoter. Cells selected for 10 days in the indicated DHT concentrations were transfected for $24 \mathrm{~h}$ with the PSA-luciferase reporter or vector control, then stimulated for $24 \mathrm{~h}$ with DHT before harvesting and assaying luciferase activity (Fig 4B). As observed in the ChIP assay, selection in decreasing androgen reduced the magnitude of reporter expression upon DHT stimulation, specifically in LNCaP 33 cells. These results are consistent with dose-dependent loss of AR promoter binding and transcriptional activity after prolonged low androgen selection.

To relate loss of AR function in LNCaP 81 cells to the overall status of glucuronidation pathway function, we quantified downstream metabolites and expression levels of gene products dependent on those metabolites. Figure 5A illustrates the three direct fates of UDPglucuronate in prostate tumor cells: (1) hyaluronan synthase (HAS) enzymes alternately polymerize glucuronate and $\mathrm{N}$-acetylglucosamine using the UDP-esterified precursors; (2) UGT enzymes produce androgen-glucuronides including conjugates of testosterone, DHT, or androstanediol; (3) UDP-xylose synthase 1 (UXS1) decarboxylates UDP-glcA to produce UDP-xylose (UDP-xyl), which is an essential initiating precursor for all chondroitin sulfate and heparan sulfate proteoglycans, as well as a precursor for specialized trisaccharides needed for surface presentation of proteoglycan receptors such as Notch1. UDP-glc and UDP-glcA are the substrate and product of UGDH, respectively. Similarly, UDP-glcA and UDP-xyl are the substrate and product of UXS1. Absolute quantification of these nucleotide sugars revealed significantly altered profiles in LNCaP 81 relative to LNCaP 33 cells (Fig 5B). Replotting the ratio of UDP-glcA to UDP-glc provides a measure of the relative flux through UGDH, while the ratio of UDP-xyl to UDP-glcA indicates flux through UXS1 (Fig 5C). From these plots, it was evident that LNCaP 81 had significantly higher levels of UDPglcA and >2-fold higher product/substrate ratio for UGDH than LNCaP 33 cells, while the UXS1 product/substrate ratio was only $\approx 30 \%$ in $\mathrm{LNCaP} 81$ relative to $\mathrm{LNCaP} 33$.

Higher UDP-glcA in LNCaP 81 cells was not secreted as DHT-glucuronide (Fig 5D) so we measured expression of UXS1 and Notch 1 to assess flux through this arm of the pathway. UXS1 levels in androgen-depleted and refed cells was modestly higher in LNCaP 81 cells at all DHT doses and did not exhibit significant androgen dependence (Fig 5E). Expression of the xylose-modified mature proteoglycan Notch 1 was significantly androgen stimulated at all doses in LNCaP 33 cells following a short-term androgen depletion (Fig 5F).

Importantly, overall steady state expression of both the full-length (FL) Notch 1 protein and the mature cleaved Notch 1 intracellular/transmembrane domain (NTM) indicative of the correctly glycosylated state of the protein was increased $\approx 5$-fold and $\approx 2$-fold, respectively, in LNCaP 81 cells (Fig 5G).

To confirm and extend these results, we also profiled metabolites and Notch 1 expression in $22 \mathrm{Rv} 1$ and PC 3 cells. The overall responses of $22 \mathrm{Rv} 1$ cells were very similar to those of LNCaP 81 cells. Specifically, steady state UDP-sugar levels were comparable in magnitude and the ratios exhibited the same trends of higher UDP-glcA and lower UDP-xyl (Fig S2AS2B). DHT-glucuronide secretion was not detectable in either 22Rv1 or PC3 media, so we compared glucuronidation of androstanediol (A-diol), the immediate major product of DHT catabolism. A-diol-glucuronide was $\approx 80-100$-fold lower in both lines, relative to LNCaP 33 
and 81 (Fig S2C). UXS1 expression was not different from LNCaP 33 (Fig S2D), but Notch 1 NTM and FL were also increased 2-fold and 6-fold, respectively, in 22Rv1 cells (Fig S2ES2F). Collectively, results of these analyses show that altered metabolite profiles indicated differences in partitioning of nucleotide sugar precursors that underlie altered glucuronidation potential of LNCaP 81 and 22Rv1 cells. Such partitioning is consistent with prioritized use of nucleotide sugars for the production of secreted proteoglycans by LNCaP 81 cells, which permits the cells to retain intracellular androgens.

\section{Stable UGDH knockdown increases basal AR-mediated gene expression and DHT glucuronidation}

To test the role of UGDH in androgen dependent gene expression, we compared LNCaP 33 cells clonally selected for shRNA knockdown of UGDH or expression of a non-targeting control vector. Knockdown of UGDH led to significant increases in expression of both PSA and UGT2B17, with varied impact on AR expression (Fig 6A-6D). As observed in LNCaP81 and 22Rv1 cells, UXS1 levels remained largely unchanged (Fig 6E). However, in contrast to the profiles of these lines, the expression of cell surface Notch 1 was $>50 \%$ reduced when UGDH was depleted (Fig 6F). Furthermore, DHT-glucuronide (DHT-G) content of the cell-conditioned media from the UGDH knockdown lines was $\approx 4$-fold higher (Fig 6G), and A-diol-glucuronide was 1.5-2-fold higher (Fig 6H), relative to the control lines. These results are consistent with androgen-dependent cells preferentially partitioning UDP-glcA precursors to the glucuronidation pathway in conditions during which UDP-glcA is limiting, at the expense of proteoglycan production.

A consequence of persistent UDP-glcA deficiency could be exaggerated cellular androgen depletion, which could stimulate expression of androgen biosynthetic enzymes. Therefore, we examined expression of two representative enzymes, HSD17B3 and HSD3B1, which participate in the conversion of androgen precursors such as DHEA, estrogens, and cholesterol, into the potent AR ligand DHT. Both enzymes were expressed at detectable levels in all cell lines tested, and both were elevated in $\mathrm{LNCaP} 81$ relative to $\mathrm{LNCaP} 33$ (Fig 7A,7C). HSD17B3 was not affected by UGDH knockdown (Fig 7B), but HSD3B1 was reduced $\approx 50 \%$ in UGDH knockdown lines (Fig 7D). Therefore, elevated androgen glucuronidation in the absence of UGDH, which would be expected to diminish cellular androgen levels, did not act globally to increase enzyme capacity for biosynthesis of androgens in LNCaP 33 cells. However, the increased expression of biosynthetic enzymes in LNCaP 81 cells would be predicted to increase androgens available for glucuronidation, but this was not reflected in glucuronide production (Fig 5D). We further examined the expression of the ARv7 splice variant, which lacks the androgen binding domain and has been shown to initiate expression of a separate pool of genes from those under control of the full length AR. Only 22Rv1 cells expressed detectable levels of ARv7 (Fig S3A), which could contribute to the partial constitutive derepression of UGT2B17 in those cells, but does not explain the similar outcome in the LNCaP lines and UGDH knockdown sublines. Finally, we quantified basal expression of the pioneer transcription factor FoxA1, which is required for UGT2B17 expression. However, levels were unchanged in any of the lines, except PC3 (Fig S3B). In the latter, the low levels of FoxA1 could partly account for the virtually undetectable level of UGT2B17. Collectively, the results suggest altered expression 
of ARv7, FoxA1, and HSD enzymes are not general underlying factors mediating metabolite partitioning, but that metabolite fate priorities are dependent on UGDH expression.

\section{Discussion}

Mechanisms by which prostate tumor cells lose dependence on extracellular androgens involve extensive feedback-regulated signaling and crosstalk. Maintaining narrow concentration ranges of DHT for optimal AR-mediated gene expression and function depends on a balance between exogenous hormone precursors, intracellular synthesis, and inactivation. In this study, we compared the function of the androgen-regulated inactivation pathway in an isogenic LNCaP model of androgen dependent versus castration resistant prostate cancer, to determine the specific role of glucuronidation precursor availability in promoting and sustaining androgen dependent gene expression in prostate tumor cells. Despite apparent reduced glucuronide output, $\mathrm{LNCaP} 81$ castration resistant tumor cells expressed higher levels of UGDH, UGT2B15, and UGT2B17, the component enzymes of the glucuronidation pathway. However, the blunted androgen responsive activation of UGDH and PSA, and the minimal repression of AR and UGT2B17, were consistent with the obvious loss of AR promoter binding and transcriptional activation we also measured. Analysis of the UDP-sugar pools and flux through pathways downstream of UDP-glcA production revealed that these precursors were channeled instead through proteoglycan and glycosaminoglycan biosynthetic pathways, leading to increased surface expression of Notch 1. Depletion of UDP-glcA by knockdown of UGDH in androgen dependent LNCaP cells stimulated glucuronide production and reduced Notch 1. Overall, these results suggest that UDP-sugar levels may have a greater impact on androgen sensitivity than previously appreciated, by mechanisms independent of protein expression alone.

We previously found that androgen-stimulated UGDH expression increased DHTglucuronide content of $\mathrm{LNCaP}$ conditioned media in androgen dependent LNCaP 33 cells despite strong concurrent suppression of UGT2B15 and UGT2B17 [20], which demonstrated that precursor availability could drive glucuronidation with minimal glucuronosyltransferase expression. In contrast, we show here that LNCaP 81 cells have increased expression of UGDH and UGT, and elevated UDP-glcA precursors, but fail to secrete significant DHT-G. This is the more puzzling as the LNCaP 81 cells have been reported to have higher levels of intracellular androgen biosynthesis [29], which would be expected to contribute further to increased androgen-glucuronide pools. Thus, we sought to identify alternative pathways activated concurrently with the loss of androgen dependence. Gene expression profiling previously revealed alterations in ErbB2 and Cyclin $\mathrm{H}$ in LNCaP 81, which may promote more rapid cell proliferation independently of androgens [23]. Importantly, this report also found elevated expression of PSMA in these cells, which is a prostate-specific cell surface chondroitin sulfate proteoglycan. This is consistent with our finding that Notch 1 is also upregulated and suggests a global repatterning of UDP-glcA fates to preferentially support proteoglycan synthesis.

UDP-glcA is an immediate precursor for UDP-xyl synthesis, which is essential for all proteoglycan production. However, UGDH is strongly inhibited by UDP-xyl in vitro [30] and this is a potential endogenous regulator of UDP-glcA flux through different pathways. 
To investigate possible effects of UDP-xyl production on UGDH function, we quantified UDP-xyl. Levels are very low relative to the other UDP-sugars (Fig 5B and S2). In comparing LNCaP 33 and 81 cells, UDP-xyl appears to be correlated inversely with steady state UDP-glcA, which is consistent with the elevated UGDH and UDP-glcA in LNCaP 81 cells. Similar results were observed in 22Rv1 cells. The significantly lower UDP-xyl levels reflect rapid use of UDP-xyl in downstream proteoglycan synthesis, such that its levels do not build and inhibit UDP-glcA production, as they do in LNCaP 33. UDP-xylose is required for processing of Notch 1 and presentation at the plasma membrane so fluxes in UDP-xyl levels would be predicted to affect both full length and processed Notch 1 levels [31], as we observed (Fig 5G and S2). Since large amounts of UDP-glcA are also required for high level proteoglycan synthesis, which occurs in the Golgi apparatus, while DHTglucuronide formation is catalyzed in the ER, the UDP-glcA may be preferentially delivered to the Golgi, thereby restricting its availability for androgen glucuronidation in $\mathrm{LNCaP} 81$ and $22 \mathrm{Rv} 1$ cells.

We also found $\mathrm{LNCaP} 81$ cells synthesize $\approx 2$-fold more hyaluronan than LNCaP 33 cells [20]. This is a third alternative limiting factor for UDP-glcA availability in LNCaP 81 cells. However, we have shown that hyaluronan production suppresses cell proliferation, which is not compatible with the selected rapidly proliferating phenotype of the LNCaP 81 cells. Nonetheless, it is important to consider that prioritizing UDP-glcA to elevating proteoglycan production also requires sufficient nutrient availability to support significantly increased protein synthesis. It may be for this reason that we saw LNCaP 33 and 81 cells had similar rates of Notch 1 surface expression in 1\% serum containing media following androgen depletion (Fig 5F) while the steady state Notch 1 levels in standard 10\% serum containing media were higher in the LNCaP 81 cells. Overall, these results suggest the pathway favored by prostate tumor cells selected to avoid dependence on androgens is proteoglycan synthesis, because it competes with growth-slowing processes like hyaluronan production and androgen glucuronidation. This is further supported by the observation that UGDH expression is elevated in cell lines modeling CRPC, and its knockdown reprioritizes use of the limited UDP-glcA for glucuronidation, significantly diminishing proteoglycan synthesis.

While it is reasonable to propose that repatterned metabolite use is a driver of prostate tumor cell loss of androgen dependence, other possible functional changes cannot be ruled out. Our analysis of AR expression showed no evidence of altered splice variant expression between LNCaP 33 and 81 cells (Fig 3 and S3), so we do not think ligand-independent AR function is the primary factor in the blunted responses we observed in expression of PSA and suppression of UGT (Fig 1 and S1). The AR has also been shown to undergo multiple posttranslational modifications that modulate its subcellular localization and its association with transcriptional coregulation complexes [32,9]. We did not examine or quantify these modifications so it is possible that androgen-independent gene expression changes occur by this mechanism. An additional component of androgen elimination is the organic anion transport protein family (OATP), also known as solute carrier proteins denoted SLCO, which are the transporters by which androgen conjugates leave and enter the cell. Altered expression of specific members of this transporter family has been correlated with castration resistant and/or metastatic prostate cancer progression [33-35]. Thus, the reduced secretion of DHT-G could occur as a result of such changes, which would be expected to limit 
production of androgen-glucuronides and prevent use of UDP-glcA in this arm of the pathway.

Androgen glucuronidation enzymes have been implicated in prostate cancer risk, metastasis, and response to anti-androgen therapy in clinical and mechanistic studies $[36,37,17,16,14$, $13,18]$. Here, we found an association between dampened AR-mediated gene expression and increased glucuronidation potential as measured by UDP-glcA precursor availability and expression of enzymes in the pathway, which are hallmarks in loss of cellular androgen responsiveness. We propose a novel mechanism by which cellular metabolite flux regulates androgen dependence through partitioning of glucuronidation precursors. The knockdown of UGDH and consequent perturbation of cellular UDP-sugar metabolites yielded an overall phenotype that may be more responsive to androgen deprivation. Features of the stable UGDH knockdown included increased androgen elimination, decreased proteoglycan production, and reduced HSD3B1 expression. In prostate tumor cells, the biosynthesis of testosterone and DHT from the alternative circulating precursor DHEA-S is directly controlled by HSD3B1. Thus, the net outcome of UGDH inhibition would be to deplete all intracellular androgens while preventing the proteoglycan "escape route". It will be interesting to determine whether loss of UGDH in castration resistant tumor cells can reverse metabolite partitioning and restore androgen sensitivity. These insights may provide new diagnostic tools or therapeutic targets to predict castration resistant recurrence.

\section{Supplementary Material}

Refer to Web version on PubMed Central for supplementary material.

\section{Acknowledgments}

This work was supported by NIH R01 CA165574 (MAS), NIH P20 GM103489 (MAS), NIH P30GM103335 (JS, JJB, MAS) and NIH R21 R21CA185993 (MAS, JJB, JEM).

\section{References}

1. Siegel RL, Miller KD, Jemal A. Cancer statistics, 2016. CA Cancer J Clin. 2016; 66(1):7-30. DOI: 10.3322/caac.21332 [PubMed: 26742998]

2. Harris WP, Mostaghel EA, Nelson PS, Montgomery B. Androgen deprivation therapy: progress in understanding mechanisms of resistance and optimizing androgen depletion. Nat Clin Pract Urol. 2009; 6(2):76-85. ncpuro1296 [pii]. DOI: 10.1038/ncpuro1296 [PubMed: 19198621]

3. Pienta KJ, Smith DC. Advances in prostate cancer chemotherapy: a new era begins. CA Cancer J Clin. 2005; 55(5):300-318. quiz 323-305. [PubMed: 16166075]

4. Katzenwadel A, Wolf P. Androgen deprivation of prostate cancer: Leading to a therapeutic dead end. Cancer Lett. 2015; 367(1):12-17. DOI: 10.1016/j.canlet.2015.06.021 [PubMed: 26185001]

5. Attar RM, Takimoto CH, Gottardis MM. Castration-resistant prostate cancer: locking up the molecular escape routes. Clin Cancer Res. 2009; 15(10):3251-3255. 1078-0432.CCR-08-1171 [pii]. DOI: 10.1158/1078-0432.CCR-08-1171 [PubMed: 19447877]

6. Chen CD, Welsbie DS, Tran C, Baek SH, Chen R, Vessella R, Rosenfeld MG, Sawyers CL. Molecular determinants of resistance to antiandrogen therapy. Nat Med. 2004; 10(1):33-39. [pii]. DOI: 10.1038/nm972nm972 [PubMed: 14702632]

7. Zhang A, Zhang J, Plymate S, Mostaghel EA. Classical and Non-Classical Roles for Pre-Receptor Control of DHT Metabolism in Prostate Cancer Progression. Horm Cancer. 2016; doi: 10.1007/ s12672-016-0250-9 
8. Sun S, Sprenger CC, Vessella RL, Haugk K, Soriano K, Mostaghel EA, Page ST, et al. Castration resistance in human prostate cancer is conferred by a frequently occurring androgen receptor splice variant. J Clin Invest. 2010; 120(8):2715-2730. DOI: 10.1172/JCI41824 [PubMed: 20644256]

9. Ware KE, Garcia-Blanco MA, Armstrong AJ, Dehm SM. Biologic and clinical significance of androgen receptor variants in castration resistant prostate cancer. Endocr Relat Cancer. 2014; 21(4):T87-T103. DOI: 10.1530/ERC-13-0470 [PubMed: 24859991]

10. Turgeon D, Carrier JS, Levesque E, Hum DW, Belanger A. Relative enzymatic activity, protein stability, and tissue distribution of human steroid-metabolizing UGT2B subfamily members. Endocrinology. 2001; 142(2):778-787. [PubMed: 11159850]

11. Chouinard S, Pelletier G, Belanger A, Barbier O. Cellular specific expression of the androgenconjugating enzymes UGT2B15 and UGT2B17 in the human prostate epithelium. Endocr Res. 2004; 30(4):717-725. [PubMed: 15666817]

12. Guillemette C, Hum DW, Belanger A. Regulation of steroid glucuronosyltransferase activities and transcripts by androgen in the human prostatic cancer LNCaP cell line. Endocrinology. 1996; 137(7):2872-2879. [PubMed: 8770908]

13. Chouinard S, Barbier O, Belanger A. UDP-glucuronosyltransferase 2B15 (UGT2B15) and UGT2B17 enzymes are major determinants of the androgen response in prostate cancer LNCaP cells. J Biol Chem. 2007; 282(46):33466-33474. M703370200 [pii]. DOI: 10.1074/ jbc.M703370200 [PubMed: 17848572]

14. Chouinard S, Yueh MF, Tukey RH, Giton F, Fiet J, Pelletier G, Barbier O, Belanger A. Inactivation by UDP-glucuronosyltransferase enzymes: The end of androgen signaling. J Steroid Biochem Mol Biol. 2008; 109(3-5):247-253. S0960-0760(08)00069-1 [pii]. DOI: 10.1016/j.jsbmb.2008.03.016 [PubMed: 18467088]

15. Guillemette C, Levesque E, Beaulieu M, Turgeon D, Hum DW, Belanger A. Differential regulation of two uridine diphospho-glucuronosyltransferases, UGT2B15 and UGT2B17, in human prostate LNCaP cells. Endocrinology. 1997; 138(7):2998-3005. [PubMed: 9202245]

16. Park J, Chen L, Shade K, Lazarus P, Seigne J, Patterson S, Helal M, Pow-Sang J. Asp85tyr polymorphism in the udp-glucuronosyltransferase (UGT) $2 \mathrm{~B} 15$ gene and the risk of prostate cancer. J Urol. 2004; 171(6 Pt 1):2484-2488. 00005392-200406000-00117 [pii]. [PubMed: 15126881]

17. Park J, Chen L, Ratnashinge L, Sellers TA, Tanner JP, Lee JH, Dossett N, et al. Deletion polymorphism of UDP-glucuronosyltransferase 2B17 and risk of prostate cancer in African American and Caucasian men. Cancer Epidemiol Biomarkers Prev. 2006; 15(8):1473-1478. [PubMed: 16896035]

18. Montgomery RB, Mostaghel EA, Vessella R, Hess DL, Kalhorn TF, Higano CS, True LD, Nelson PS. Maintenance of intratumoral androgens in metastatic prostate cancer: a mechanism for castration-resistant tumor growth. Cancer Res. 2008; 68(11):4447-4454. 68/11/4447 [pii]. DOI: 10.1158/0008-5472.CAN-08-0249 [PubMed: 18519708]

19. Spicer AP, Kaback LA, Smith TJ, Seldin MF. Molecular cloning and characterization of the human and mouse UDP-glucose dehydrogenase genes. J Biol Chem. 1998; 273(39):25117-25124. [PubMed: 9737970]

20. Wei Q, Galbenus R, Raza A, Cerny RL, Simpson MA. Androgen-stimulated UDP-glucose dehydrogenase expression limits prostate androgen availability without impacting hyaluronan levels. Cancer Res. 2009; 69(6):2332-2339. 0008-5472.CAN-08-3083 [pii]. DOI: 10.1158/0008-5472.CAN-08-3083 [PubMed: 19244115]

21. Huang D, Casale GP, Tian J, Lele SM, Pisarev VM, Simpson MA, Hemstreet GP 3rd. Udp-glucose dehydrogenase as a novel field-specific candidate biomarker of prostate cancer. Int J Cancer. 2010; 126(2):315-327. DOI: 10.1002/ijc.24820 [PubMed: 19676054]

22. Igawa T, Lin FF, Lee MS, Karan D, Batra SK, Lin MF. Establishment and characterization of androgen-independent human prostate cancer LNCaP cell model. Prostate. 2002; 50(4):222-235. [pii]. DOI: 10.1002/pros.10054 [PubMed: 11870800]

23. Karan D, Kelly DL, Rizzino A, Lin MF, Batra SK. Expression profile of differentially-regulated genes during progression of androgen-independent growth in human prostate cancer cells. Carcinogenesis. 2002; 23(6):967-975. [PubMed: 12082018] 
24. Garcia AD, Chavez JL, Mechref Y. Sugar nucleotide quantification using multiple reaction monitoring liquid chromatography/tandem mass spectrometry. Rapid Commun Mass Spectrom. 2013; 27(15):1794-1800. DOI: 10.1002/rcm.6631 [PubMed: 23821573]

25. Nakayama K, Maeda Y, Jigami Y. Interaction of GDP-4-keto-6-deoxymannose-3,5-epimerase-4reductase with GDP-mannose-4,6-dehydratase stabilizes the enzyme activity for formation of GDP-fucose from GDP-mannose. Glycobiology. 2003; 13(10):673-680. DOI: 10.1093/glycob/ cwg099 [PubMed: 12881408]

26. Wang Q, Carroll JS, Brown M. Spatial and temporal recruitment of androgen receptor and its coactivators involves chromosomal looping and polymerase tracking. Mol Cell. 2005; 19(5):631642. DOI: 10.1016/j.molcel.2005.07.018 [PubMed: 16137620]

27. Bao BY, Chuang BF, Wang Q, Sartor O, Balk SP, Brown M, Kantoff PW, Lee GS. Androgen receptor mediates the expression of UDP-glucuronosyltransferase 2 B15 and B17 genes. Prostate. 2008; 68(8):839-848. DOI: 10.1002/pros.20749 [PubMed: 18302198]

28. Shi XB, Xue L, Zou JX, Gandour-Edwards R, Chen H, deVere White RW. Prolonged androgen receptor loading onto chromatin and the efficient recruitment of p160 coactivators contribute to androgen-independent growth of prostate cancer cells. Prostate. 2008; 68(16):1816-1826. DOI: 10.1002/pros.20849 [PubMed: 18780293]

29. Dillard PR, Lin MF, Khan SA. Androgen-independent prostate cancer cells acquire the complete steroidogenic potential of synthesizing testosterone from cholesterol. Mol Cell Endocrinol. 2008; 295(1-2):115-120. S0303-7207(08)00357-2 [pii]. DOI: 10.1016/j.mce.2008.08.013 [PubMed: 18782595]

30. Kadirvelraj R, Sennett NC, Custer GS, Phillips RS, Wood ZA. Hysteresis and negative cooperativity in human UDP-glucose dehydrogenase. Biochemistry. 2013; 52(8):1456-1465. DOI: 10.1021/bi301593c [PubMed: 23363239]

31. Sethi MK, Buettner FF, Ashikov A, Krylov VB, Takeuchi H, Nifantiev NE, Haltiwanger RS, Gerardy-Schahn R, Bakker H. Molecular cloning of a xylosyltransferase that transfers the second xylose to O-glucosylated epidermal growth factor repeats of notch. J Biol Chem. 2012; 287(4): 2739-2748. DOI: 10.1074/jbc.M111.302406 [PubMed: 22117070]

32. Sprenger CC, Plymate SR. The link between androgen receptor splice variants and castrationresistant prostate cancer. Horm Cancer. 2014; 5(4):207-217. DOI: 10.1007/s12672-014-0177-y [PubMed: 24798453]

33. Arakawa H, Nakanishi T, Yanagihara C, Nishimoto T, Wakayama T, Mizokami A, Namiki M, Kawai K, Tamai I. Enhanced expression of organic anion transporting polypeptides (OATPs) in androgen receptor-positive prostate cancer cells: possible role of OATP1A2 in adaptive cell growth under androgen-depleted conditions. Biochem Pharmacol. 2012; 84(8):1070-1077. DOI: 10.1016/ j.bcp.2012.07.026 [PubMed: 22864060]

34. Fujimoto N, Kubo T, Inatomi H, Bui HT, Shiota M, Sho T, Matsumoto T. Polymorphisms of the androgen transporting gene SLCO2B1 may influence the castration resistance of prostate cancer and the racial differences in response to androgen deprivation. Prostate Cancer Prostatic Dis. 2013; 16(4):336-340. DOI: 10.1038/pcan.2013.23 [PubMed: 23896625]

35. Wright JL, Kwon EM, Ostrander EA, Montgomery RB, Lin DW, Vessella R, Stanford JL, Mostaghel EA. Expression of SLCO transport genes in castration-resistant prostate cancer and impact of genetic variation in SLCO1B3 and SLCO2B1 on prostate cancer outcomes. Cancer Epidemiol Biomarkers Prev. 2011; 20(4):619-627. DOI: 10.1158/1055-9965.EPI-10-1023 [PubMed: 21266523]

36. Cai L, Huang W, Chou KC. Prostate cancer with variants in CYP17 and UGT2B17 genes: a metaanalysis. Protein Pept Lett. 2012; 19(1):62-69. [PubMed: 21919858]

37. Levesque E, Beaulieu M, Green MD, Tephly TR, Belanger A, Hum DW. Isolation and characterization of UGT2B15(Y85): a UDP-glucuronosyltransferase encoded by a polymorphic gene. Pharmacogenetics. 1997; 7(4):317-325. [PubMed: 9295060] 



Fig. 1. Castration resistant prostate tumor cells exhibit blunted ligand-dependent AR responses, with higher levels of glucuronidation enzymes relative to androgen sensitive controls

LNCaP 33 and LNCaP 81 cells were cultured in androgen depleted media for $48 \mathrm{~h}$, followed by $48 \mathrm{~h}$ of treatment with the indicated doses of DHT. Total cell lysates were analyzed in triplicate by immunoblots probed for the indicated proteins: A) UGDH; B) PSA; C) AR; D) UGT2B17. Densitometric quantification was normalized to tubulin and plotted as mean \pm SEM of fold changes relative to the LNCaP $330 \mathrm{nM}$ treatment. $* \mathrm{p}<0.05$ relative to $\mathrm{LNCaP}$ 33, 0 nM DHT; $\ddagger$ p $<0.05$ for $\mathrm{LNCaP} 81$ relative to LNCaP 33 at the indicated DHT treatment. 

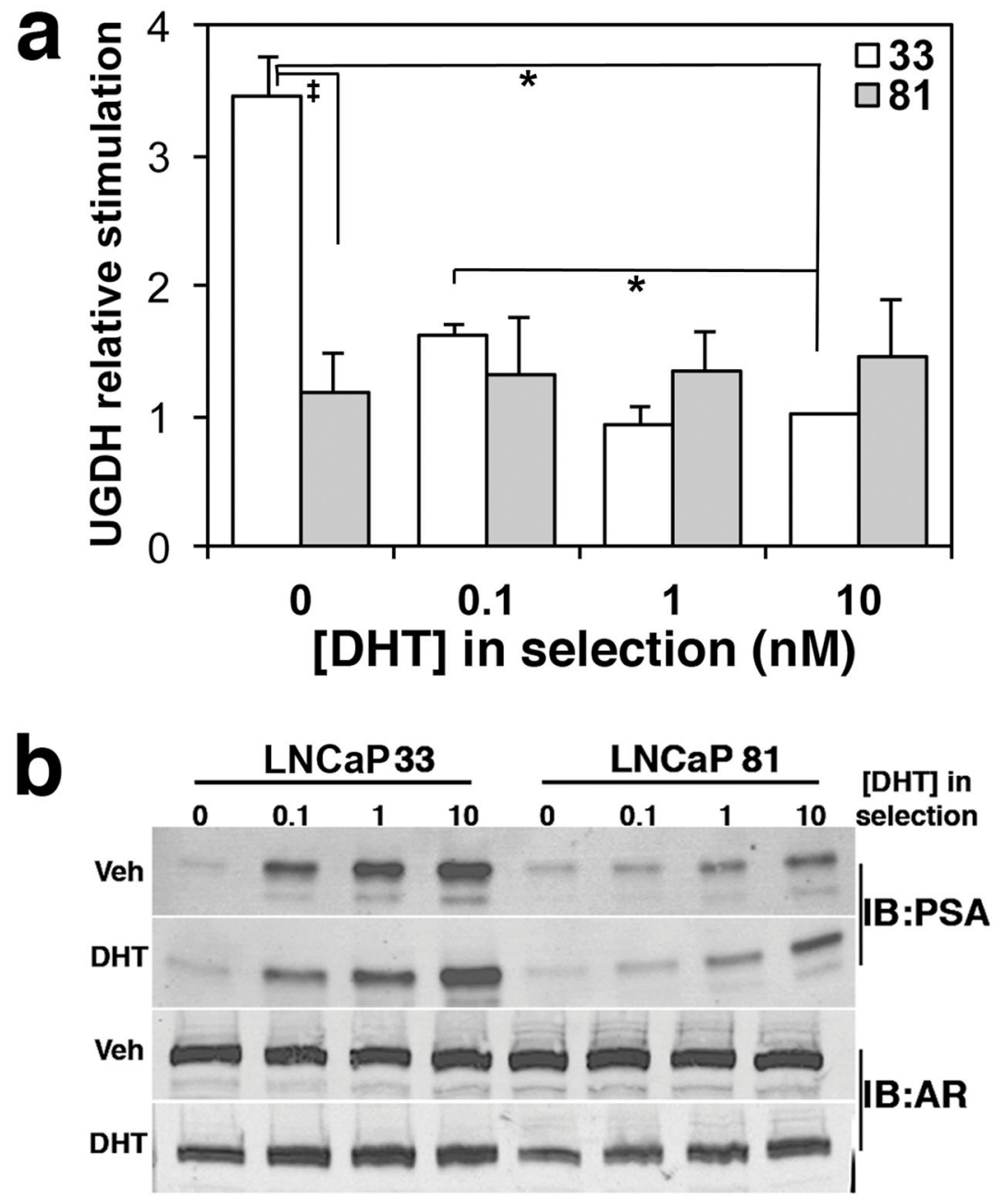

Fig. 2. Re-expression of AR-activated genes UGDH and PSA is dose dependent following prolonged androgen depletion

LNCaP 33 and 81 cells were selected for ten days in the indicated DHT concentrations.

Prior to harvest, media were removed and replaced with media containing vehicle or $10 \mathrm{nM}$ DHT for 24 h. (A) Equivalent amounts of protein were immunoblotted for UGDH and tubulin. UGDH expression was quantified, normalized to tubulin and plotted as the ratio of $24 \mathrm{~h}$ DHT-treated versus vehicle-treated expression to illustrate stimulated expression. Mean \pm SEM is plotted; * $\mathrm{p}<0.05$ relative to $\mathrm{LNCaP} 33$ at $10 \mathrm{nM}$ DHT; $\ddagger \mathrm{p}<0.05$ for $\mathrm{LNCaP} 81$ relative to LNCaP 33 at the indicated DHT treatment. (B) Blots in (A) were reprobed for PSA (34 kDa) and AR (102 kDa). 


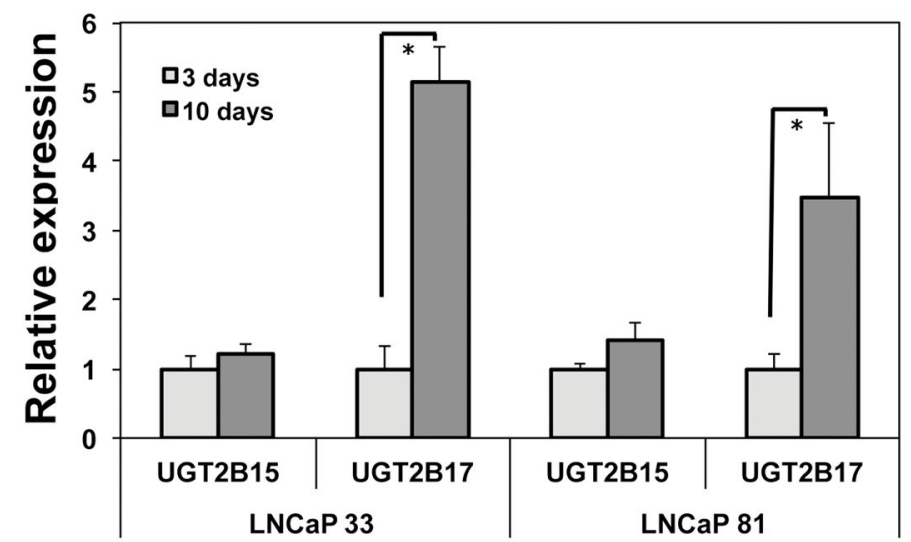

b $\frac{5}{g}$
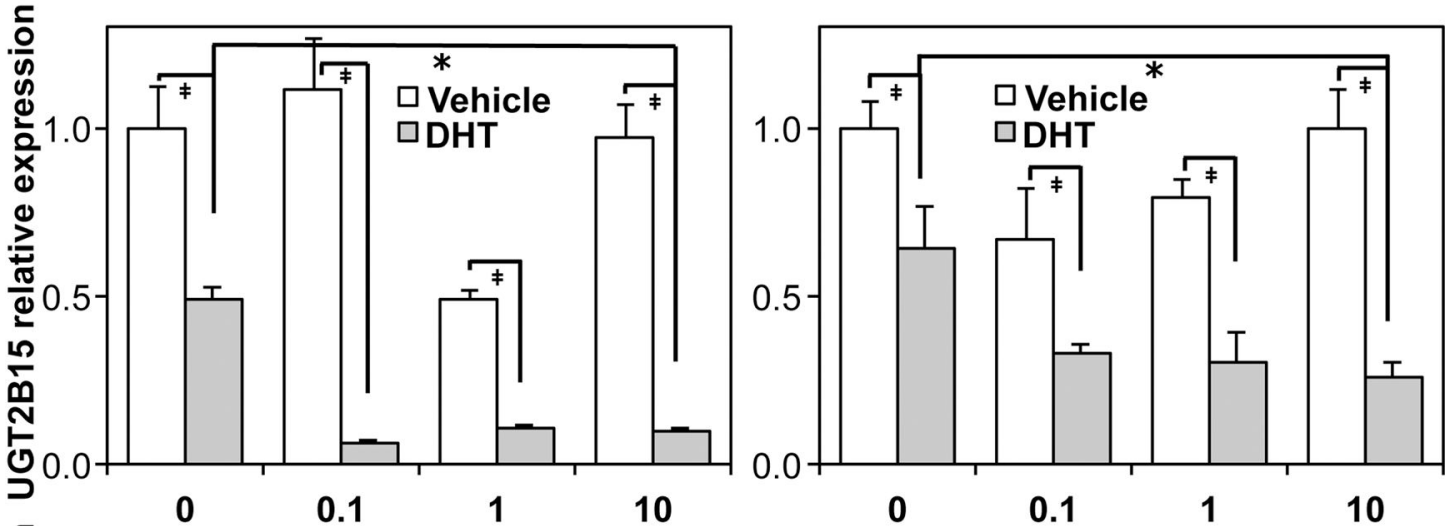

c

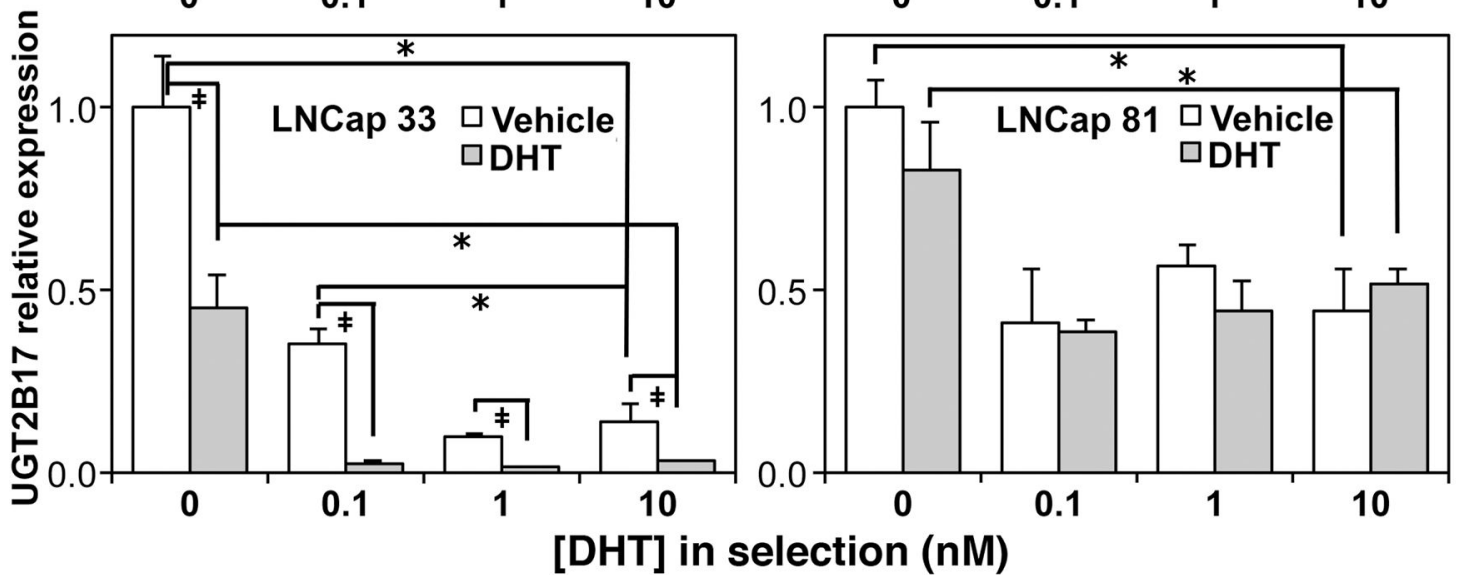

Fig. 3. Strong androgen dependent repression of UGT enzymes is maintained in androgen sensitive LNCaP 33 cells but lost in castration resistant LNCaP 81 cells

LNCaP 33 and 81 cells were selected for ten days in the absence of DHT (A) or in the indicated DHT concentrations (B and C). Prior to harvest, media were removed and replaced with media containing vehicle or $10 \mathrm{nM}$ DHT for $24 \mathrm{~h}$. Total RNA was extracted and analyzed for UGT2B15 (B) and UGT2B17 (C) expression by qRT-PCR. Mean \pm SEM of triplicate assays is plotted. In (A), expression was compared in cells cultured only in androgen-depleted media for the indicated times, without DHT stimulation; * $\mathrm{p}<0.05$ for 10 days relative to 3 days. For panels $\mathrm{B}$ and $\mathrm{C},{ }^{*} \mathrm{p}<0.05$, DHT deficient selection relative to 10 $\mathrm{nM}$ selection; $\ddagger \mathrm{p}<0.05$ for vehicle vs. DHT in each selection. 

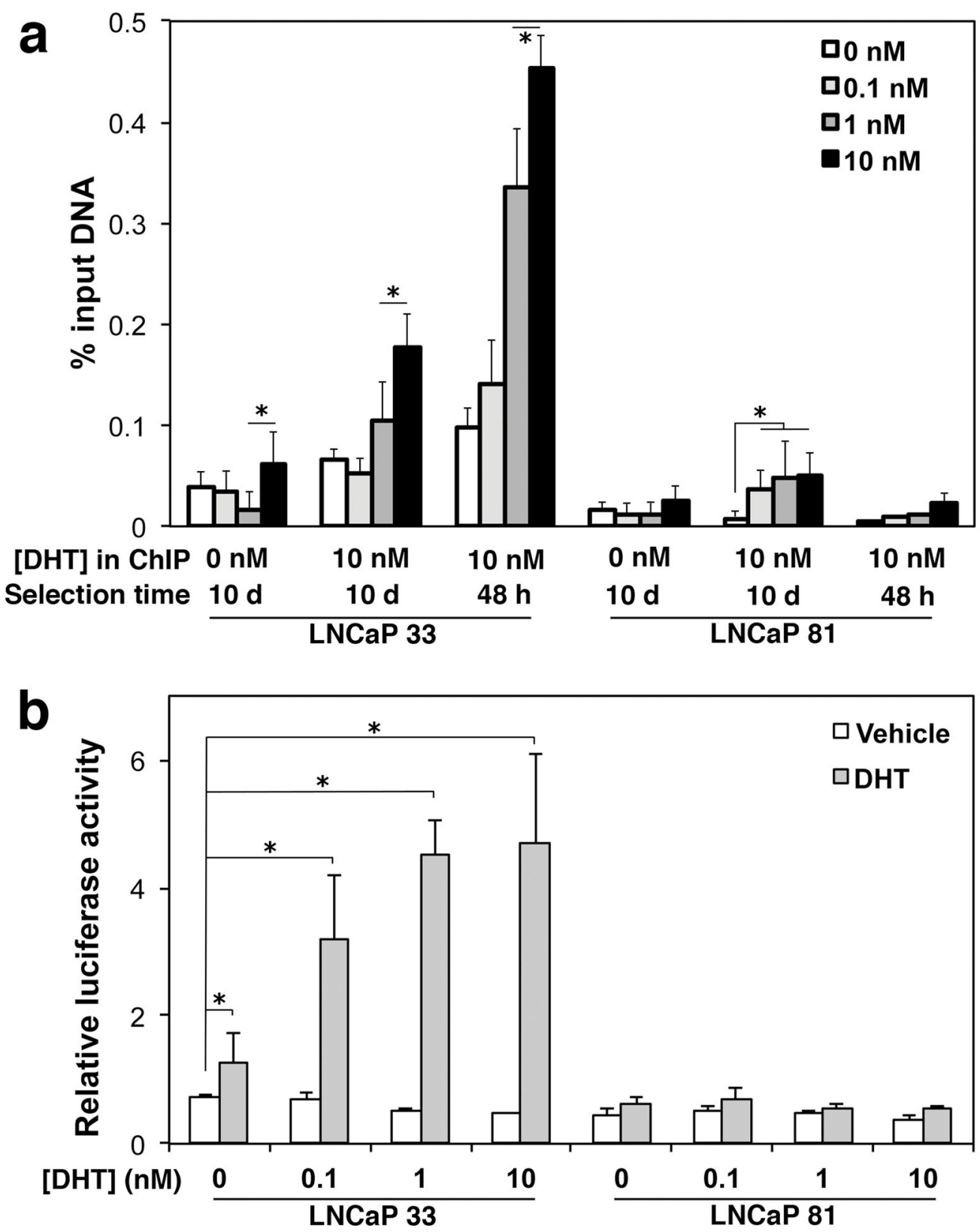

Fig. 4. Prolonged androgen depletion dampens ligand-dependent function of the AR in LNCaP 33 and 81 cells

Cells were selected in $0,0.1,1$, or $10 \mathrm{nM}$ DHT for $48 \mathrm{~h}$ or for 10 days. Selected cells were then treated with vehicle or $10 \mathrm{nM}$ DHT prior to assay. (A) Genomic DNA was analyzed by anti-AR ChIP. AR occupancy of the PSA promoter was quantified by qPCR in technical duplicates and plotted as \% input (fraction of total immunoprecipitated DNA amplified by the gene-specific primers). Data shown represent mean \pm SEM for one of three assays replicated with identical trends. (B) Following selection, cells were co-transfected with PSA-Luc and Renilla reporter constructs and subsequently treated with vehicle or $10 \mathrm{nM}$ DHT for another $24 \mathrm{~h}$ before assaying luciferase activity. Mean \pm SD of normalized activity 
measured in triplicate is plotted. $* \mathrm{p}<0.05$ for DHT restimulated relative to unstimulated at 0 $\mathrm{nM}$. 

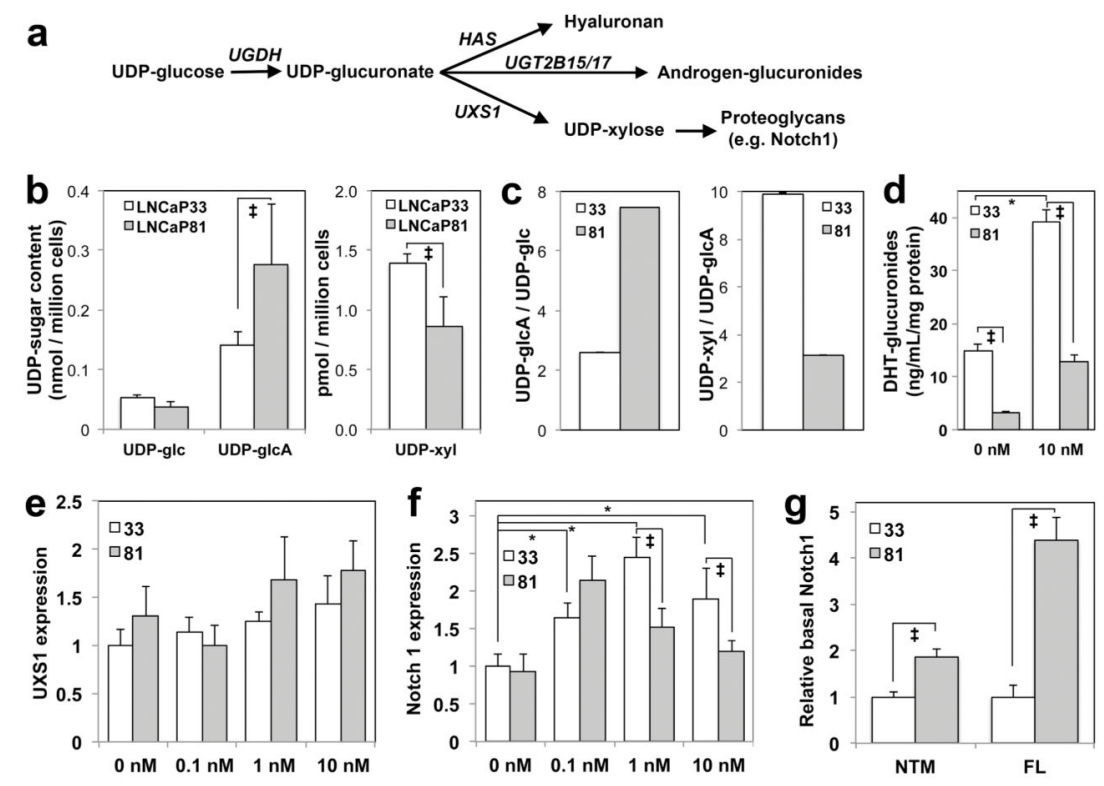

Fig. 5. Metabolite analysis of glucuronidation pathway components

A) Schematic of the glucuronidation pathway and its alternatives. B) UDP-sugar content was quantified by LC-MS in whole lysates from LNCaP 33 and LNCaP 81 cells cultured in standard serum-containing media. Mean \pm SD is plotted. C) The ratios of UDP-glucuronate (UDP-glcA) to UDP-glucose (UDP-glc), and UDP-xylose (UDP-xyl) to UDP-glcA were calculated from mean values in (B) to illustrate steady state intracellular flux through UGDH and UXS1, respectively. Note that the scale for UDP-xyl/UDP-glcA is $\times 10^{-3}$. D) DHT-G secretion was quantified from conditioned media of each cell line and plotted as mean \pm SD. $\mathrm{E}$ and F) LNCaP 33 and LNCaP 81 cells were cultured in androgen depleted media for 48 hours, followed by 48 hours of treatment with the indicated doses of DHT. Total cell lysates were analyzed in triplicate by immunoblots probed for UXS1 (E) or Notch 1 (F). G) Lysates from cells cultured in standard media were analyzed by immunoblot for Notch 1. NTM indicates quantification of the $\approx 120 \mathrm{kDa}$ intracellular and transmembrane domain of Notch 1 ; FL denotes the $\approx 272 \mathrm{kDa}$ full length Notch 1 protein. In panels $\mathrm{E}-\mathrm{G}$, densitometric quantification was normalized to tubulin and mean \pm SEM is plotted. * $\mathrm{p}<0.05$ relative to LNCaP 33, 0 nM DHT; $\$ \mathrm{p}<0.05$ for LNCaP 81 relative to LNCaP 33 at the indicated DHT treatment. 

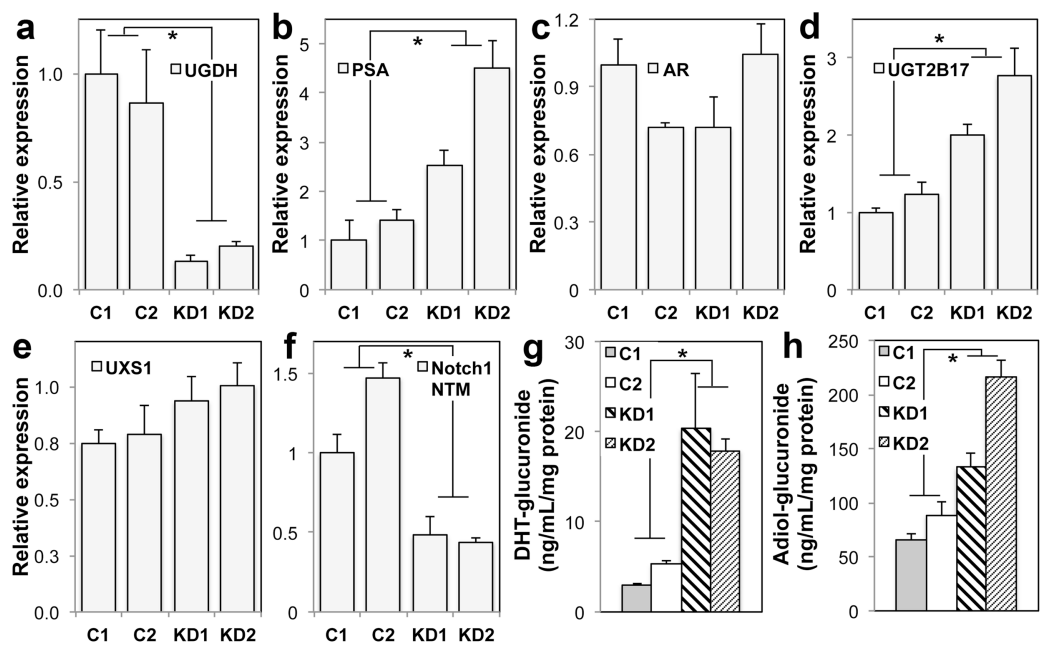

Fig. 6. Stable UGDH knockdown increases basal AR-mediated gene expression and androgen glucuronidation, while diminishing Notch1 proteoglycan expression

Two individual clones of LNCaP 33 cells selected for stable UGDH-targeted shRNA

knockdown or non-targeted shRNA controls were grown in standard steroid-replete media. Whole cell lysates were analyzed by western blot for (A) UGDH, (B) PSA, (C) AR, (D) UGT2B17, (E) UXS1, or (F) the intracellular and transmembrane domain of Notch1 (NTM).

Expression was normalized to tubulin and plotted as mean \pm SEM for three biological replicates of each clone. (G) DHT-G or (H) Adiol-G secretion was quantified from conditioned media of each clone and plotted as mean \pm SD. In all panels, $* \mathrm{p}<0.05$ relative to values for $\mathrm{C} 1$. 

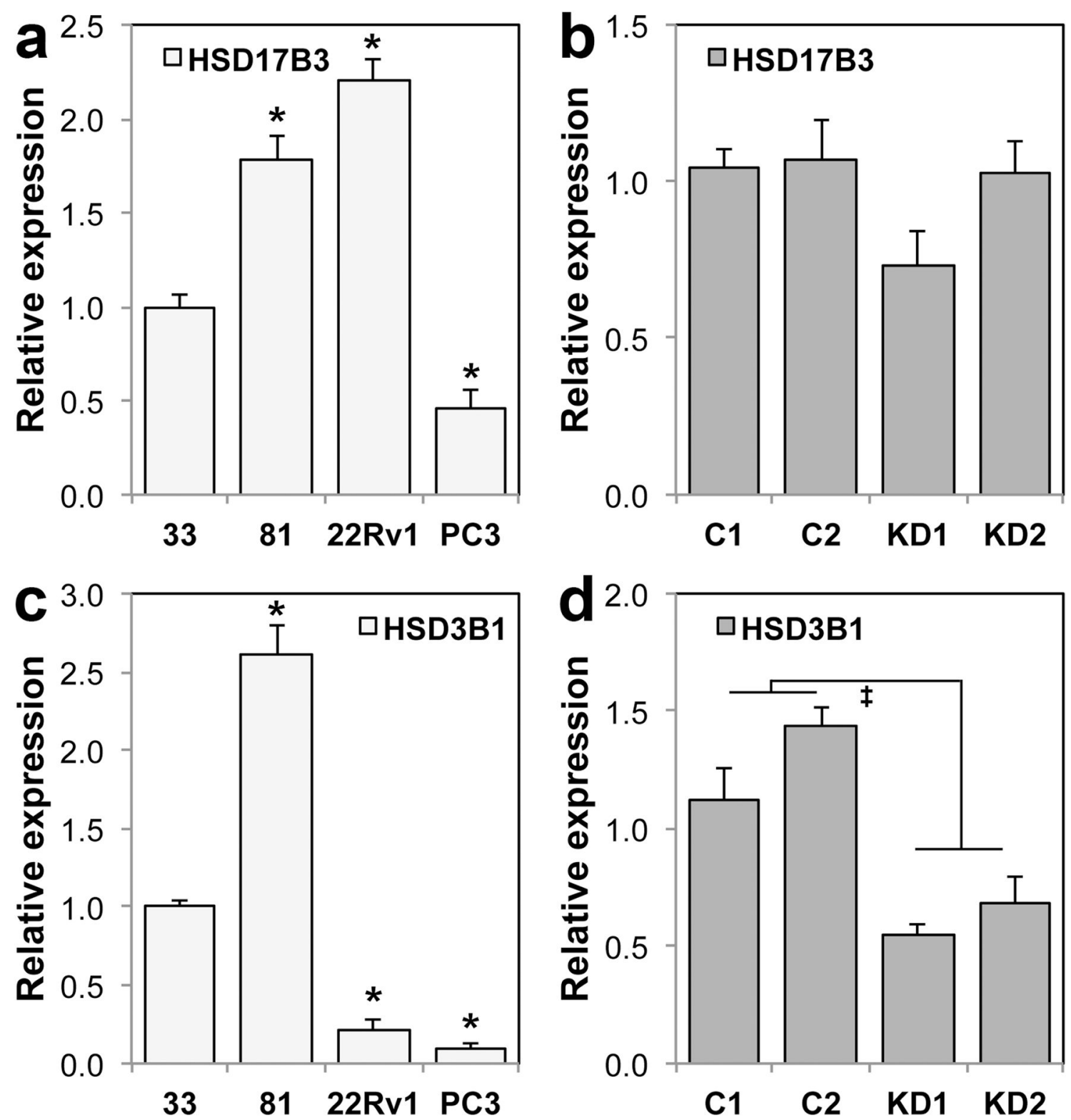

Fig. 7. UGDH knockdown reduces HSD3B1

LNCaP 33, 81, 22Rv1, and PC3 cell lines (A and C) or LNCaP 33 control and UGDH knockdown clones (B and D) were grown in standard steroid-replete media. Total cell lysates were normalized by protein content and analyzed in triplicate by immunoblots probed for HSD17B3 (A and B) or HSD3B1 (C and D). Densitometric quantification was normalized to tubulin and plotted as mean \pm SEM of fold changes relative to LNCaP 33 or $\mathrm{C} 1 .{ }^{*} \mathrm{p}<0.05$ relative to $\mathrm{LNCaP} 33 ; \neq \mathrm{p}<0.05$ relative to $\mathrm{C} 1$. 